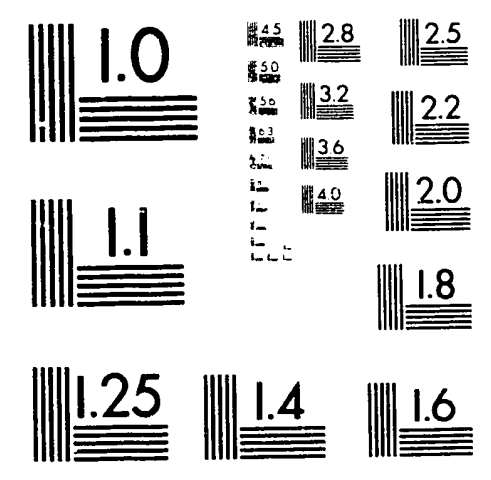



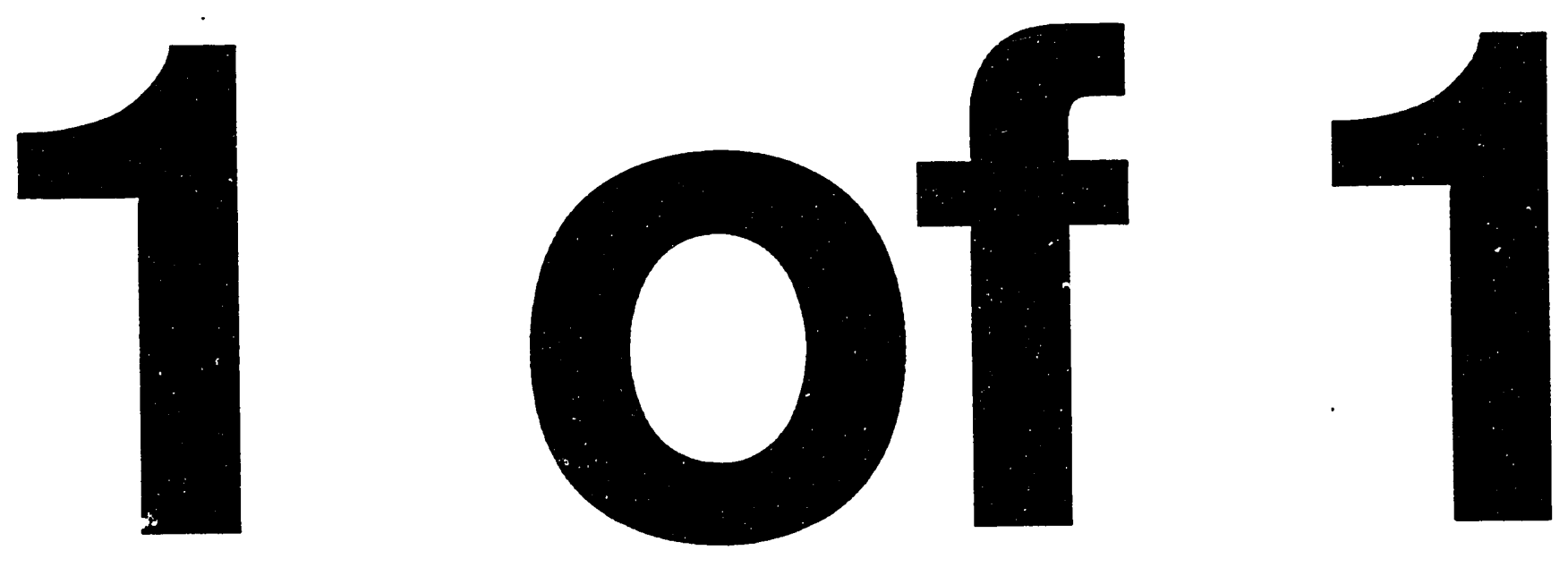


\title{
THERMODYNAMIC PROPERTIES OF PULVERIZED COAL DURING RAPID HEATING DEVOLATILIZATION PROCESSES
}

\section{QUARTERLY PROGRESS REPORT \\ January - March 1993}

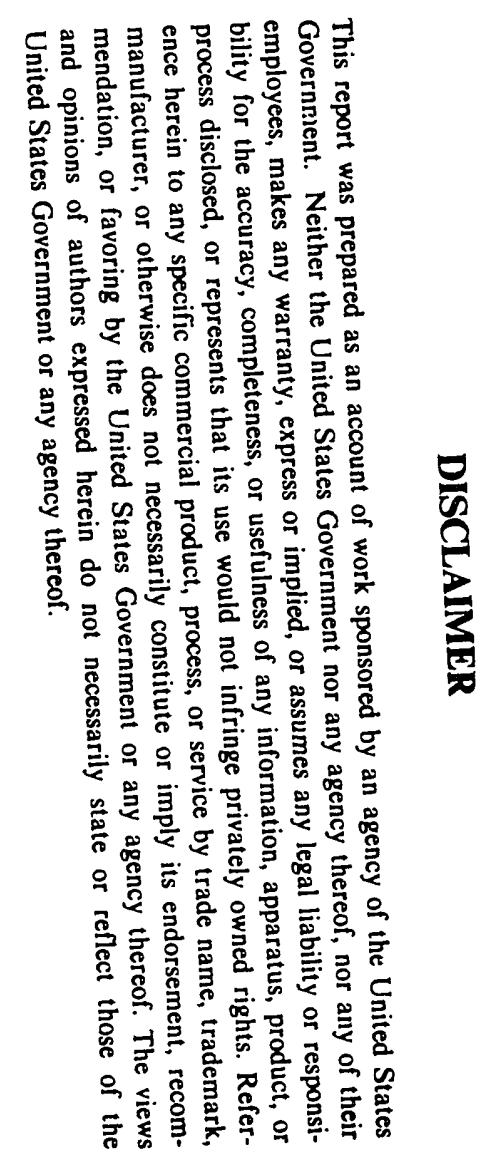

\author{
Prepared by \\ W.M. Proscia \\ J.D. Freihaut \\ United Technologies Research Center \\ 411 Silver Lane \\ E. Hartford, CT 06108 \\ For \\ U.S. Department of Energy \\ Pittsburgh Energy Technology Center \\ Contract No. DE-AC22-92PC92176 \\ DOE Contracting Officer's Representative \\ Clifford A. Smith
}

July 1993

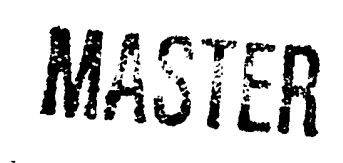




\section{CONTENTS}

1.0 Executive Summary .1

2.0 Introduction and Overview of Technical Objectives 2

3.0 Task 5: Heat of Thermal Decomposition of Volatile Coal Samples ..5

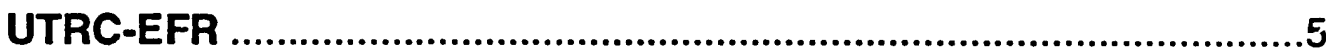

EFR Devolatilization Experiments ................................................6

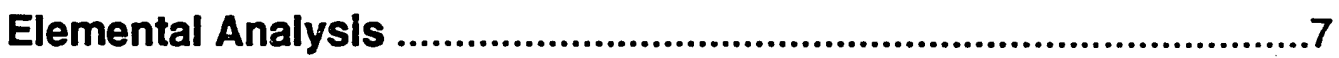

EFR Product Yields ........................................................................

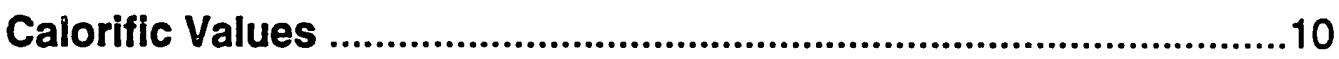

4.0 Task 10. Morphological Characterization of Coal/Char

Samples as a Function of Extent of Devolatilization .........12

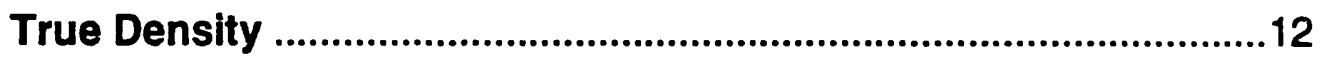

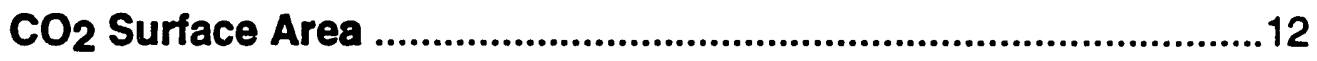

Mercury Porisimetry .........................................................................13

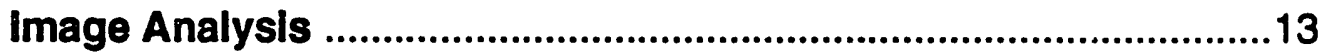

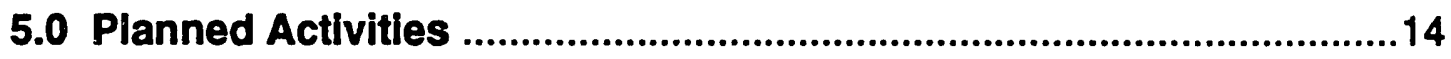

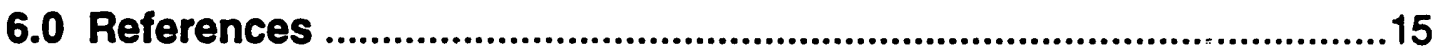




\subsection{Executive Summary}

Knowledge of the thermodynamic and morphological properties of coal associated with rapid heating decomposition pathways is essential to progress in coal utilization technology. Specifically, knowledge of the heat of devolatilization, surface area and density of coal as a function of rank characteristics, temperature and extent of devolatilization in the context of rapid heating conditions is required both, for the fundamental determination of kinetic parameters of coal devolatilization, and to refine existing devolatilization sub-models used in comprehensive coal combustion codes.

The objective of this research is to obtain data on the thermodynamic properties and morphology of coal under conditions of rapid heating. Specifically, the total heat of devolatilization, external surface area, BET surface area and true density will be measured for representative coal samples. In addition, for one coal, the contribution of each of the following components to the overall heat of devolatilization will be measured: the specific heat of coaVchar during devolatilization, the heat of thermal decomposition of the coal, the specific heat capacity of tars, and the heat of vaporization of tars.

Last quarter, matched tar and char samples were generated in the UTRC EFR for 75-106 $\mu \mathrm{m}$ particle size cuts of the two study coals, PSOC 1451D and 1561D. Elemental analysis and microbomb calorimetry results for the tars and chars have been completed in the current quarter. Light gas yields have also been determined from the FT-IR sfeetra acquired during the EFR runs. The product yields and chemical characteristics are all in agreement with the results of previous investigations in this laboratory using smaller particle sizes. The tar and char samples are being used to determine the thermodynamic properties and morphology of coal as a function of extent of reaction.

Morphological characterization of the parent coal samples has been completed by the Uriversity of Pittsburgh. Results are presented for true density, $\mathrm{CO}_{2}$ surface area, mercury porisimetry, and particle size and shape measuremenits using image analysis.

Work on Task 3, Low Temperature Specific Heat Capacity of Volatile Coal Samples, is nearly completed and will be reported on next quarter. Task 4, Heat of Devolatilization of Volatile Coal Samples, will be initiated. The heat of thermal decomposition of PSOC 1451D (Task 5) will be calculated from the data reported here. The Task 10 effort, Morphological Characterization of CoaVChar Samples as a Function of Extent of Devolatilization, will continue at the University of Pittsburgh. Work will focus on measurement of the morphological characteristics of the char samples as a function of extent of reaction. 


\subsection{Introduction and Overview of Technical Objectives}

\section{Introduction}

Knowledge of the thermodynamic and morphological properties of coal associated with rapid heating decomposition pathways is essential to progress in coal utilization technology. Specifically, knowledge of the heat of devolatilization, surface area and density of coal as a function of rank characteristics, temperature and extent of devolatilization in the context of rapid heating conditions is essential to the fundamental determination of kinetic parameters of coal devolatilization. These same properties are alsc needed to refine existing devolatilization sub-models utilized in large-scale modeling of coal combustion systems.

In many instances the kinetic analysis of rapid coal devolatilization data acquired in laboratory reactors depends on an assumed set of heat capacity, heat of devolatilization and particle morphology parameters. In other cases, attempts to measure particle temperatures during devolatilization (Refs. $1,2,3$ ) lead to results that are not in agreement either with a priori determinations obtained with energy balance expressions using estimations of thermodynamic properties of coal found in the open literature or inert, carbon-based calibration standards used to calibrate the reactor system. Although it is not always clear if the discrepancies are due to inadequate thermodynamic properties of the particle during devolatilization, particle shape factors, inadequate emittance values or some combination of these factors, it is now apparent that independent determinations of these properties in heating conditions characteristic of disperse phase coal utilization technology is necessary. Moreover, since it is now well-established that the energy transfer rate between an environment and injected coal particles, significantly influences the observable devolatilization response time of the particles (Ref. 4), the independent determination of the specific heat and devolatilization heat of reaction of coal is necessary.

\section{Objective}

The objective of this research is to obtain data on the thermodynamic properties and morphology of coal under conditions of rapid heating. Specifically, the total heat of devolatilization, external surface area, BET surface area and true density will be measured for representative coal samples. The coal ranks to be investigated will include a high volatile A bituminous (PSOC 1451D) and a low volatile bituminous (PSOC 1516D). An anthracite (PSOC 1468) will be used as a non-volatile coal reference. In addition, for one coal, the contribution of each of the following components to the overall heat of devolatilization will be measured: the specific heat of coal/char during devolatilization, the heat of thermal decomposition of the coal, the specific heat capacity of tars, and the heat of vaporization of tars. 


\section{Project Tasks}

The work required to complete the objectives of this investigation has been divided into eleven tasks. Each of these tasks is summarized below. The details of the technical approach have been described previously (Ref. 5).

Task 1 - Project Work Plan

UTRC shall provide the DOE with a detailed Project Plan within 30 days of contract initiationi. Work on no other tasks shall proceed until written approval of this plan is obtained by UTRC from the DOE Pijject Manager. The Project Plan shall include a Management Plan, Milestone Schedule, Status Report, and Cost Plan.

Task 2 - Calibration of the Heated Grid Calorimeter

UTRC shall measure the specific heat of the non-volatile reference coal (anthracite, PSOC 1468) from $25^{\circ} \mathrm{C}$ to $800^{\circ} \mathrm{C}$ at heaiirig rates of $1000^{\circ} \mathrm{C} / \mathrm{sec}$ and lower in the heated grid (HG) device. The values will be established relative to NBS calorimeter standards for differential scanning calorimeter (DSC) and differential thermal analysis (DTA) samples. The sensitivity of the heated grid device for determining thermodynamic properties at high heating rates will be established before proceeding with Tasks 3-9.

Task 3 - Low Temperature Specific Heat Capacity of Volatile Coal Samples

UTRC shall measure the specific heat Cipacity for a minimum of one coal sample over the temperature range of $25^{\circ} \mathrm{C}$ to $300^{\circ} \mathrm{C}$. The measurements will be conducted at heating rates of $1000^{\circ} \mathrm{Cisec}$ and lower in the UTRC HG.

Task 4 - Heat of Devolatilization of Volatile Coal Samples

UTRC shall measure the heat of devolatilization for a minimum of one coal sample over the temperature range of $25^{\circ} \mathrm{C}$ to $800^{\circ} \mathrm{C}$ using heating rates of $1000^{\circ} \mathrm{C} / \mathrm{sec}$ in the calibrated HG. Devolatilization product characteristics will be determined to ensure the devolatilization pathway is that followed in the entrained flow reactor (EFR).

Task 5 - Heat of Thermal Decomposition of Volatile Coal Samples

UTRC shall measure, using the EFR and microbomb calorimeter (MBC), the heat of decomposition for a minimum of one coal sample by: (1) devolatilizing the coal in the EFR, (2) determining the char, tar and gas yields, (3) measuring the tar and char elemental compositions, (4) determining the heat of combustion of the char and tar products using the MBC, (5) estimating the heat of combustion of the gaseous products, and (6) using Hess's and Kirchoff's laws to derive the heat of decomposition. 
Task 6 - Specific Heat and Heat of Fusion of Tars from Rapid Heating

UTRC shall measure the specific heat and heat of fusion of tar samples for a minimum of one coal sample over the temperature range from $25^{\circ} \mathrm{C}$ to $300^{\circ} \mathrm{C}$ using the $H G$ and tar samples generated in the EFR.

Task 7 - Heat of Vaporization of Tars from Rapid Heating

UTRC shall measure the heat of vaporization of tar samples for a minimum of one coal sample over the temperature range from $300^{\circ} \mathrm{C}$ to $700^{\circ} \mathrm{C}$ using the $H G$ and tar samples generated in the EFR.

Task 8 - Specific Heat of Char Samples

UTRC shall measure the specific heat of the coalchar as a function of extent of devolatilization and temperature for a minimum of one coal sample using partially devolatilized samples from the EFR and the HG.

Task 9 - Comparison of Directly Measured Heat of Devolatilization and Thermodynamic Function Determined Value

UTRC shall determine the heat of devolatilization for a minimilm of one coal sample based on independent measurements of heat of decomposition (Task 5), specific heat and heat of fusion of tars (Task 6), heat of vaporization of tars (Task 7), and specific heat of coal/chars (Task 3 and Task 8 ). This value shall be compared and contrasted to the directly measured heat of devolatilization values from $25^{\circ} \mathrm{C}$ to $800^{\circ}$ C obtained in Task 4.

Task 10 - Morphological Characterization of Coal/Char Samples as a Function of Extent of Devolatilization

UTRC shall characterize statistically representative samples of coaVchar particles as a function of extent of devolatilization for a minimum of one coal sample. The characterization shall be with respect to combustion related reactivity parameters such as swelling and cenosphere development, $\mathrm{CO}_{2}$ or $\mathrm{O}_{2}$ surface areas, and helium (true) density.

Task 11 - Reporting

UTRC shall comply with all required reporting over the 18 month period of the contract. 


\subsection{Task 5. Heat of Thermal Decomposition of Volatile Coal Samples}

The objective of this task is to determine the heat of decomposition of PSOC 1451D by: (1) devolatilizing the coal in the entrained flow reactor (EFR) to generate matched char and tar samples as a function of extent of devolatilization, (2) determining the char, tar and light gas yields, (3) measuring the tar and char elemental composition, (4) determining the heat of combustion of char and tar products using a microbomb calorimeter (MBC), (5) estimating the heat of combustion of the gaseous products, and (6) applying Hess's Law to determine the heat of decomposition.

\section{UTRC-EFR}

The essential components of the UTRC entrained flow reactor (EFR) are shown in Figures 1-3. The reactor consists of a coal feeder, a drop tube furnace using argon as the entrainment gas, and a product collection and separation system. The EFR is operated without preheating the entrainment gas so that gas temperatures remain below wall temperatures throughout the reactor. Extra-particle gas-phase reactions of tars are minimized by operating in this mode. This is in contrast to the operation of most entrained flow reactors, where the entrainment gas temperature is matched to the reactor wall temperature. The heat transfer environment of the reactor has been characterized and documented in previo: investigations (Refs. 4,6,7).

The coal feed system consists of a jet-stirred, fluidized-bod supply reservoir connected to the reactor primary stream injector via a narrow bcie transfer tube. The feed system is capable of sustained delivery of optically thin streams of constant mass delivery rate, provided the feeder is loaded with a narrow particle size range initially. Particle sizes from 10 to $\mathbf{3 0 0}$ microns have been used in the feeder.

The product separation system collects the entire flow stream from the reactor into a water cooled probe. An aerosol phase separation syctem is employed to obtain charfree tar samples (Figs. 2,3). The separator is designed to "pull off," in quantities proportional to the gas split, all particles or aerosols that are less than 2 microns in diameter. Inertia carries larger particles into the char separation (cyclone train) system. The smaller particles are able to follow the curved flow streamlines and enter the aerosol separation (impactor) system. Both separation trains contain porous metal filters as final stages. Tars are primarily deposited on these filters. Detailed mass fraction analysis of the tars deposited throughout the separation system showed that only about $15 \%$ of the total tar mass is deposited in the pre-filter stages (Ref. 4). Furthermore, chemical characterization of the samples collected within the product separation system indicate that the tars collected on the final filters are representative of the collective, captured tar mass. After particulate and aerosol separation, the gas stream is analyzed on line for IR-active gases by use of a Fourier transform infrared spectrometer (FT-IR) coupled to a multipass cell having an equivalent path length of $43.5 \mathrm{~m}$. 


\section{EFR Devolatilization Experiments}

The two study coals, PSOC 1451D (a HVA bituminous coal from the Pittsburgh \#8 seam) and PSOC 1516D (a LV bituminous coal from the Lower Kittaning, FA seam) were devolatilized in the UTRC-EFR (entrained flow reactor) at four different reactor temperatures. These " $D$ " coals were supplied by DOE under an earlier contract and were size classified using the "Vortec" aerodynamic separation process. The 75-106 $\mu \mathrm{m}$ size cut is used in the performance of this contract. All EFR conditions temperature set points, carrier gas flow rates, and sampling probe position - are identical to those used during two previous contracts (Refs. 7,8). The reactor operating conditions are characterized by peak wall and gas temperatures given in Table I below.

\section{TABLE I}

\section{ENTRAINED FLOW REACTOR EXPERIMENTS}

\begin{tabular}{|c|c|c|c|c|}
\hline Run & Coal Type & Wall Temp. $\left({ }^{\circ} \mathrm{C}\right)$ & Gas Temp. $\left({ }^{\circ} \mathrm{C}\right)$ & $\begin{array}{c}\% \text { Mass } \\
\text { Loss }\end{array}$ \\
\hline EFR019 & $1451 \mathrm{D}$ & 668 & 507 & 16.7 \\
\hline EFR018 & $1451 \mathrm{D}$ & 825 & 660 & 31.0 \\
\hline EFR020 & $1451 \mathrm{D}$ & 939 & 796 & 30 \\
\hline EFR021 & $1451 \mathrm{D}$ & 1058 & 895 & 45.7 \\
\hline EFR022 & $1516 \mathrm{D}$ & 668 & 507 & $\mathrm{NM}^{*}$ \\
\hline EFR023 & $1516 \mathrm{D}$ & 825 & 660 & 8.8 \\
\hline EFR024 & $1516 \mathrm{D}$ & 939 & 796 & 19.3 \\
\hline EFR025 & $1516 \mathrm{D}$ & 1058 & 895 & 26.0 \\
\hline
\end{tabular}

* NM - Not Measurable - Volatile yields too low to measure reliably with ash tracer technique. (Mass loss in heated grid experiments at similar final temperature is 5$6 \%$.)

Sufficient quantities of matched char and tar samples were produced from the PSOC 1451D coal to complete all the necessary measurements for the performance of this contract. It was not possible to save significant quantities of tars from the PSOC $1516 \mathrm{D}$ runs. The high static charge of the samples made it difficult to remove the tars from the porous metal final filters used in the UTRC-EFR sample collection system. 


\section{Elemental Analysis}

Elemental analyses of the char samples generated in the EFR have been performed. Additional runs were required for several of the PSOC 1516D chars to improve the ash determinations. Elemental analysis for the PSOC 1451D tars has also been completed. However, analysis of the 1516D tars was not possible due to the limited amounts of sample which could be collected and saved for this coal.

The elemental composition of the chars and tars are given in Table II. The reported results are average values for 3-5 replicate analyses of each sample. These results are in excellent agre?ment with previous results at UTRC using a smaller size cut of the Vortec separatec' " $D$ " coals $(63-75 \mu \mathrm{m})$. In particular, the tars are hydrogen-rich and heteroatom-poor reiative to the parent coal (Fig. 4). The hydrogen content of the tars approaches that of the parent coal with increasing extent of devolatilization, whereas tar nitrogen content remains nearly equal to that of the parent coal.

\section{EFR Product Yields}

Mass loss values calculated using the ash tracer technique are given in Table I. These mass loss results are in agreement with data obtained under two previous UTRC investigations utilizing identical experimental conditions (Figs. 5,6). Total volatile yields for PSOC 1451 D obtained in the current investigation are compared with EFR data acquired in 1989 (Ref. 7) for 20-30 $\mu \mathrm{m}$ particles in Fig. 5. The apparent plateau in volatiles yield between $650-800^{\circ} \mathrm{C}$ is again observed. Results for zero hold time (ZHT) heated grid (HG) runs are also shown. The HG experiments were conducted in one atmosphere helium and utilized a heating rate of $1000^{\circ} \mathrm{C} / \mathrm{s}$ The heated grid yields show a steeper temperature dependence near $600^{\circ} \mathrm{C}$ thar is observed in the EFR. Current results for total volatile yields for PSOC 1516D are compared with EFR data acquired in 1991 (Ref. 8) for 63-75 $\mu \mathrm{m}$ particles in Fig. 6.

The FT-IR spectra from the EFR experiments have been quantified to ohtain light gas yields. Results for the IR-active gases are given in Table III. Relative yields of the light gases are plotted in Figures 7 and 8 for PSOC 1451D and 1516D, respectively. Relative yield data for $20-30 \mu \mathrm{m}$ diameter particles of PSOC 1451D obtained in 1989 (Ref. 7) are given in Fig. 9. Data for 63-75 $\mu \mathrm{m}$ particles of PSOC 1516D from 1991 (Ref. 8) are plotted in Fig. 10. The relative yields given in Figs. 9 and 10 were calculated by normalizing the data by the yield observed at the highest EFR temperature run $\left(1241^{\circ} \mathrm{C}\right.$ wall temp.; $1053^{\circ} \mathrm{C}$ gas temp.). Since, experiments were not conducted at this temperature for the present investigation, the relative yields in Figs 7 and 8 have been normalized to match those of the previous investigations at the $1058^{\circ} \mathrm{C}$ wall temperature $\left(895^{\circ} \mathrm{C}\right.$ gas temp.) condition.

The light gas yields obtained in the present study, using 75-105 $\mu \mathrm{m}$ particles, are in excellent agreement with results obtained for the same coals in previous investigations in this laboratory. The gas yields are dominated by methane and ethylene at gas temperatures below $660^{\circ} \mathrm{C}$. Yields of hydrogen cyanide and acetylene increase substantially at peak EFR gas temperatures above $800^{\circ} \mathrm{C}$. 


\begin{tabular}{|c|c|c|c|c|c|c|c|c|c|c|c|c|c|c|c|c|c|c|c|}
\hline & \begin{tabular}{|l|l} 
& 0 \\
& 0 \\
& 0 \\
0 & 0 \\
0 & 0 \\
0 & 0 \\
0 \\
0
\end{tabular} & & & 0 & $\begin{array}{lll}-\infty & 0 \\
0 & 0 \\
0 & 0\end{array}$ & & & & 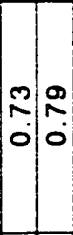 & & & & & \begin{tabular}{|c|} 
\\
- \\
$\vdots$ \\
$\vdots$ \\
0 \\
0 \\
0 \\
0
\end{tabular} & 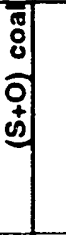 & & & $\begin{array}{l}0 \\
0 \\
0 \\
0\end{array}$ & 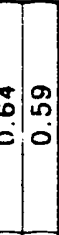 \\
\hline & 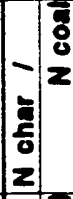 & & & 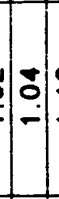 & $\because \div$ & & & & $\begin{array}{l}: \\
: \\
0\end{array}$ & $: \begin{array}{l}: 0 \\
0\end{array}$ & & & & $\mid \begin{array}{c}- \\
-5 \\
2\end{array}$ & \begin{tabular}{l|}
0 \\
z. \\
2
\end{tabular} & & & ọ & \\
\hline & 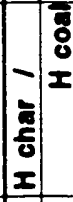 & & & $\mid \begin{array}{l}n \\
0 \\
0 \\
0\end{array}$ & \begin{tabular}{lll}
0 & 0 \\
0 & \multirow{n}{0}{} \\
0 & 0
\end{tabular} & & & & $\mid$\begin{tabular}{l|l}
0 \\
0 \\
- & 0 \\
0
\end{tabular} & $\mid \begin{array}{lll}8 & 2 \\
0 & 0\end{array}$ & & & & \begin{tabular}{|l}
- \\
$\mathbf{3}$ \\
$\mathbf{x}$
\end{tabular} & \begin{tabular}{l|} 
ă \\
x \\
\end{tabular} & & $\because$ & $\underline{0}$ & \\
\hline & $\frac{0}{x}$ & $\begin{array}{l}\text { \& } \\
0 \\
0\end{array}$ & $\stackrel{0}{\stackrel{0}{0}}$ & $: \begin{array}{l}0 \\
0 \\
0 \\
0\end{array}$ & 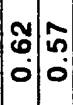 & & & & \begin{tabular}{|c|c}
$:$ & $\overline{0}$ \\
0 & 0 \\
0 & 0
\end{tabular} & {$\left[\begin{array}{ll}n & 7 \\
0 & 0\end{array}\right.$} & & & & $\frac{u}{x}$ & & $\mid \begin{array}{l}0 \\
0 \\
0 \\
0\end{array}$ & $\mid \begin{array}{l}0 \\
0 \\
0 \\
0\end{array}$ & $\mid$ & $\begin{array}{lll}\sigma \\
0\end{array}$ \\
\hline & 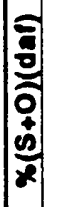 & 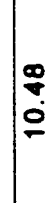 & & $\dot{b}=$ & 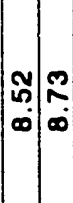 & & & & 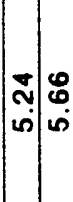 & 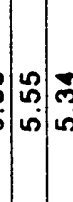 & & & & 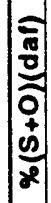 & & $\left|\begin{array}{l}\infty \\
0 \\
0\end{array}\right|$ & $\left|\begin{array}{l}n \\
\mathbf{Q} \\
\dot{0}\end{array}\right|$ & ্ָৰฺ & 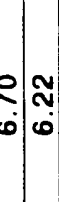 \\
\hline 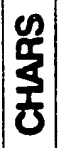 & 혈 & : & & $\because=$ & $\mid$\begin{tabular}{l}
$n$ \\
\hdashline
\end{tabular} & & & 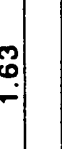 & $\because \overline{0}$ & $\mid$ & & & $\mid \begin{array}{l}0 \\
\frac{2}{\alpha} \\
\mathbf{5}\end{array}$ & $\mid \begin{array}{c}\overline{\tilde{x}} \\
\bar{z} \\
\bar{z}\end{array}$ & & $\mid \begin{array}{l}0 \\
0 \\
-1\end{array}$ & 0 & $\approx$ & $=\stackrel{8}{=} \stackrel{\square}{-}$ \\
\hline & 흘 & $\begin{array}{l}\bar{E} \\
\bar{s}\end{array}$ & & 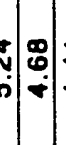 & $\begin{array}{l}=0 \\
\div \\
\div\end{array}$ & & & 告 & $\mid \begin{array}{ll}2 & 0 \\
- & +\end{array}$ & רִ & & & & 氞 & & $\left|\begin{array}{l}\overline{5} \\
\omega \\
\omega\end{array}\right|$ & $\left|\begin{array}{l}0 \\
\dot{0} \\
\dot{0}\end{array}\right|$ & $\left|\begin{array}{c}\overline{0} \\
\omega\end{array}\right|$ & 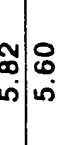 \\
\hline & 웜 & 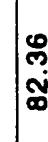 & $\overline{0}$ & 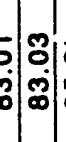 & 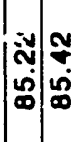 & & & | & 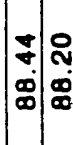 & 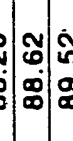 & & & & 恿 & & $\left|\begin{array}{l}\boldsymbol{D} \\
\tilde{m} \\
\dot{\Phi}\end{array}\right|$ & 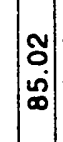 & & 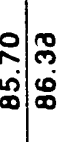 \\
\hline & 包 & • & & $5:$ & $\begin{array}{lll} & \infty \\
N & \$\end{array}$ & & & & 시: & $: \mid \stackrel{2}{\circ:}$ & & & & 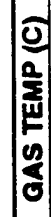 & & $1 \cdot$ & & $\left|\begin{array}{l}0 \\
0 \\
0\end{array}\right|$ & 离: \\
\hline & 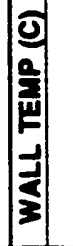 & 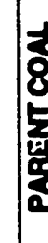 & & $: \mathbb{\infty}$ & 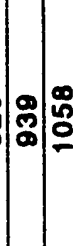 & & & 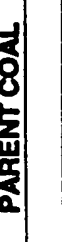 & 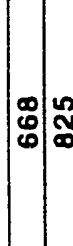 & 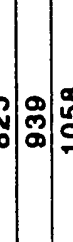 & & & & 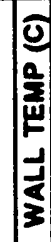 & & 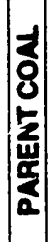 & $\left|\begin{array}{l}0 \\
0 \\
0 \\
0\end{array}\right|$ & $\stackrel{\infty}{\infty}$ & 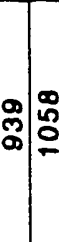 \\
\hline & 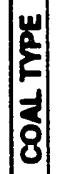 & 5 & $\frac{9}{5}$ & $\frac{0}{2}=\frac{1}{2}$ & $\frac{0}{5}$ & & & $\frac{0}{0}$ & $\frac{0}{5}$ & $\frac{0}{n}$ & & & & 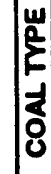 & & $\frac{0}{\mathbf{5}}$ & $\frac{0}{\frac{0}{0}}$ & $\frac{0}{5}$ & $\frac{0}{5}$ \\
\hline
\end{tabular}




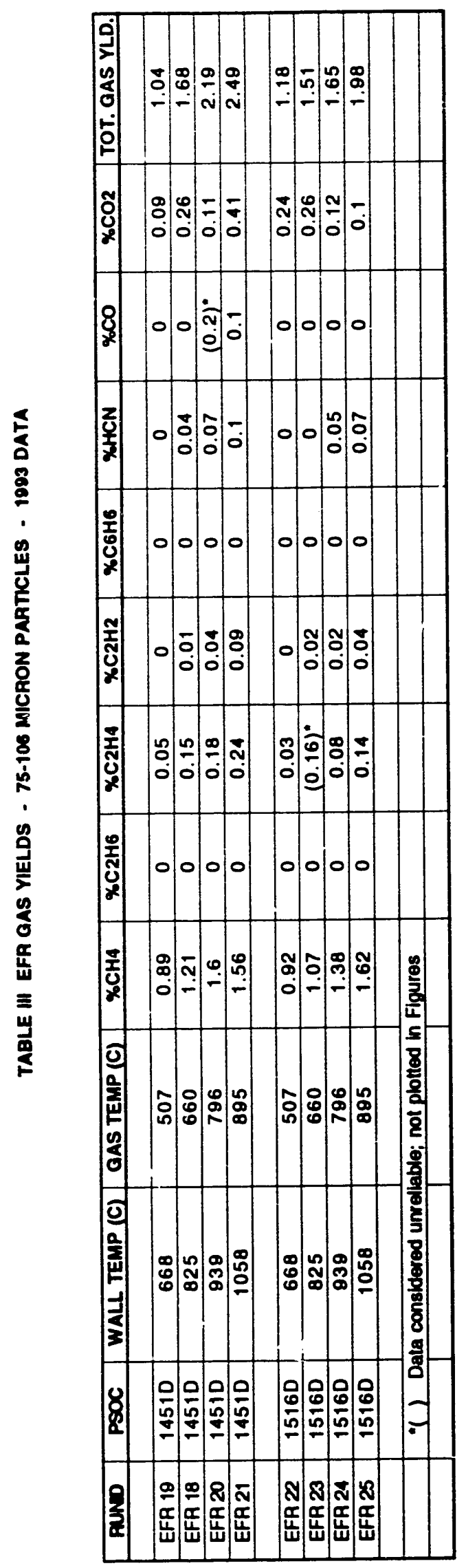




\section{Calorific Values}

Microbomb calorimeter measurements of the heats of combustion of the parent coal, char and tar samples have been performed. The raw and ash corrected calorific values of the samples are given in Table IV. Note that, for PSOC 1451D, the 75-106 $\mu \mathrm{m}$ size cut used in this investigation has a much higher ash content (13.9\%) than the $63-75 \mu \mathrm{m}$ size cut (4.09\%) used in previous DOE-funded investigations at UTRC (Refs. 7,8). However, the ash corrected calorific values for the parent coal and char samples are within $2 \%$ of those determined in the previous investigation. The ash content of the larger size cut samples of PSOC 1516D is also somewhat higher $(20.0 \%$ vs. $16.8 \%)$. The ash corrected calorific values agree within $5 \%$ to the results for the smaller particle size samples. The consistency of the microbomb calorimeter results between the two investigations provides further support for the repeatability of the UTRC entrained flow reactor experiments. 


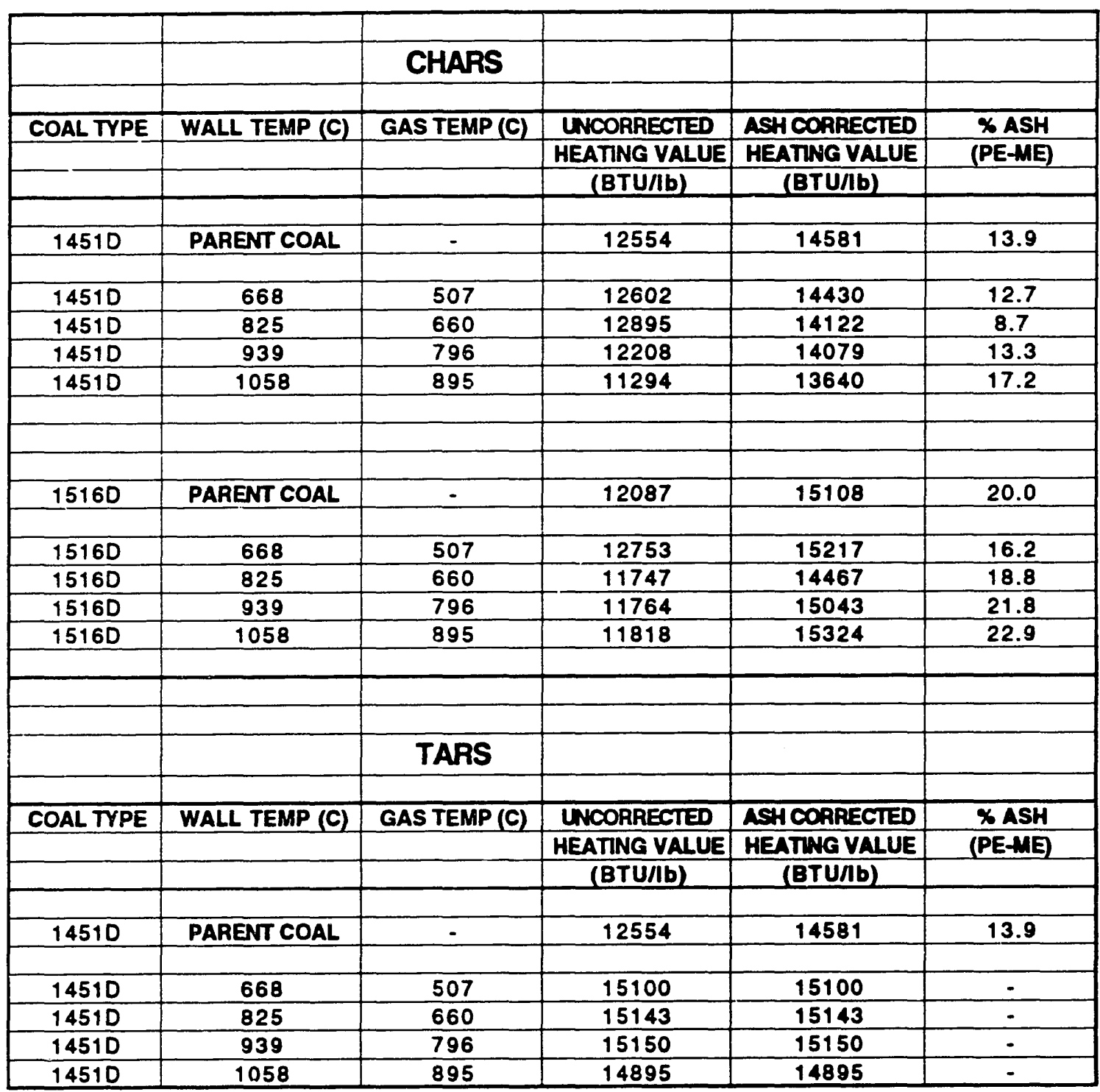




\subsection{Task 10. Morphological Characterization of Coal/Char Samples as a Function of Extent of Devolatilization.}

The overall objectives of this task are to characterize statistically representative samples of coal/char particles as a function of extent of devolatilization. The characterization shall be with respect to combustion related reactivity parameters such as swelling and cenosphere development, $\mathrm{CO}_{2}$ or $\mathrm{O}_{2}$ surface areas, and helium (true) density.

This task is being performed under subcontract to the University of Pittsburgh under the direction of Prof. George Klinzing. The subcontract was placed and work initiated in this quarter on morphology measurements of the parent coals. As a first step, the relevant equipment and instruments were checked and overhauled and required maintenance done. Trial runs were carried out using other coal samples and the results were found to be satisfactory.

\section{True Density}

True densities of the parent coal samples were determined using a Quantachrome Helium pycnometer. Arrangement was made to hook up the pycnometer to the fine vacuum system of the B.E.T. apparatus ar. ' samples were degassed in situ at room temperature for 2-3 hours before testing. Four runs were carried out for each sample. The results obtained (Table V) are in good agreement with values obtained in other investigations (Ref. 7).

\section{$\mathrm{CO}_{2}$ Surface Area}

Total surface area was determined using an ORR pore-volume analyzer from Micromeritics Corporation. Samples were degassed for 15 hours at $60^{\circ} \mathrm{C}$ and $\mathrm{CO}_{2}$ adsorption was carried out at $298^{\circ} \mathrm{K}$. Measurements were obtained at four pressures: 100, 200,400 and 600 torr. Surface areas were determined using the B.E.T. and Polanyi-Dubinin equations. The latter gives more correct results for these experiments since the maximum partial pressure is around 1/100 of the saturation pressure of $\mathrm{CO}_{2}$ (800 psi). Results are given in Table V. Maloney (Ref. 9) conducted $\mathrm{CO}_{2}$ adsorption experiments at $298 \mathrm{~K}$ for different samples from the same coal seams as the study coals. (PSOC 1099: Pittsburgh \#8 and PSOC 1133: Lower Kittaning) Surface areas calculated from the Polanyi-Dubinin equation were 170 and $220 \mathrm{~m}^{2} / \mathrm{g}$ (daf) for the HVA and LV coals, respectively. Maloney outgassed the samples for 16 hours at $110^{\circ} \mathrm{C}$ at a pressure of $10^{-5}$ torr. The results (daf) for the HVA coal are in excellent agreement. The higher outgassing temperature and smaller particle size (200 x 270 mesh; $62 \mu \mathrm{m}$ mean dia.) may account for the difference in the two sets of results for the LV bituminous coal. 


\section{Mercury Porisimetry}

A mercury porisimeter from Aminco Winslow was used to determine internal porosity and pore volume distribution. The porosities are given in Table V.

\section{Image Analysis}

A Leitz Tas plus image analyzer is being used for particle size and shape analysis using transmission microscopy. Particle size is determined by averaging three length measurements per particle. Volume is calculated assuming spherical particles. Size distributions based on number (measured) and volume (calculated) have been obtained for both types of coals. Log-probability distribution and differential distribution for size based on volume are given in Figures 11 - 14. As is evident, the distribution is not unimodal. The mean sizes are listed in Table V. Particle size distribution analysis will also be done by using a Laser Microtrac to compare results. Fractal analysis of the image data will be used to describe particle shape.

\section{TABLE V}

PARENT COAL MORPHOLOGY MEASUREMENTS

\begin{tabular}{|l|c|c|}
\hline & PSOC 1451D & PSOC 1516D \\
\hline & & \\
\hline True density (pycnometer) & $1.393 \mathrm{~g} / \mathrm{cc}$ & $1.513 \mathrm{~g} / \mathrm{cc}$ \\
\hline Bulk density (volumetric) & $0.638 \mathrm{~g} / \mathrm{cc}$ & $0.673 \mathrm{~g} / \mathrm{cc}$ \\
\hline Porosity & $54.2 \%$ & $55.5 \%$ \\
\hline B.E.T. surface area & $77 \mathrm{~m}^{2} / \mathrm{g}$ & $42 \mathrm{~m}^{2} / \mathrm{g}$ \\
\hline P-D surface area & $138 \mathrm{~m}^{2} / \mathrm{g}$ & $88 \mathrm{~m}^{2} / \mathrm{g}$ \\
\hline P-D surface area (daf) & $163 \mathrm{~m}^{2} / \mathrm{g}$ & $110 \mathrm{~m}^{2} / \mathrm{g}$ \\
\hline Pore size with max. volume & approx. $18 \mu \mathrm{m}$ & approx. $18 \mu \mathrm{m}$ \\
\hline Porosity (Mercury porisimetry) & $43.5 \%$ & $38.6 \%$ \\
\hline Number-mean size & $14.9 \mu \mathrm{m}$ & $7.6 \mu \mathrm{m}$ \\
\hline Volume-mean size & $35.8 \mu \mathrm{m}$ & $27 \mu \mathrm{m}$ \\
\hline
\end{tabular}




\subsection{Planned Activities}

The results for Task 3, Low Temperature Specific Heat Capacity of Volatile Coal Samples, which is nearly completed, will be reported on next quarter. Work on Task 4 , Heat of Devolatilization of Volatile Coal Samples, will be initiated. The heat of thermal decomposition of PSOC 1451D (Task 5) will be calculated from the data reported here. The Task 10 effort, Morphological Characterization of CoaVChar Samples as a Function of Extent of Devolatilization, will continue at the University of Pittsburgh. Work will focus on measurement of the morphological characteristics of the char samples. 


\subsection{References}

1. Fletcher, T.H., Combustion and Flame, 78 (2), 223-236 (1989).

2. Best, P.E., et al., Combustion and Flame, 66, 47-56 (1986).

3. Maloney, D.J., et al., Combustion and Flame, accepted (1990).

4. Freihaut, J.D., et al., Combustion Properties of Micronized Coal, Final Report, DEAC22-80263, DOE, PETC (1989).

5. Proscia, W.M. and Freihaut, J.D., Thermodynamic Properties Of Pulverized Coal During Rapid Heating Devolatilization Processes, Quarterly Report for July-Sept., 1992, DE-AC22-92PC92176, DOE, PETC (1992).

6. Freihaut, J.D., Proscia, W.M. and Seery, D.J., "Chemical Characteristics of Tars Produced in a Novel Low-Severity Entrained-Flow Reactor," Energy \& Fuels, 3, $692-703$ (1989).

7. Seery, D.J., et al., Kinetics of Coal Pyrolysis, Final Report, DE-AC22-84PC70768, DOE PETC (1989).

8. Freihaut, J.D. and Proscia, W.M., Investigation of the Rank Dependence of Tar Evolution, Final Report, DE-AC22-89PC89759, DOE PETC (1991).

9. Maloney, D.J., Effects of Preoxidation on Rapid Pyrolysis Behavior and Resultant Char Structure of Caking Coais, Ph.D. Dissertation, Dept. of Materials Science and Engineering, The Pennsylvania State University, 1983. 


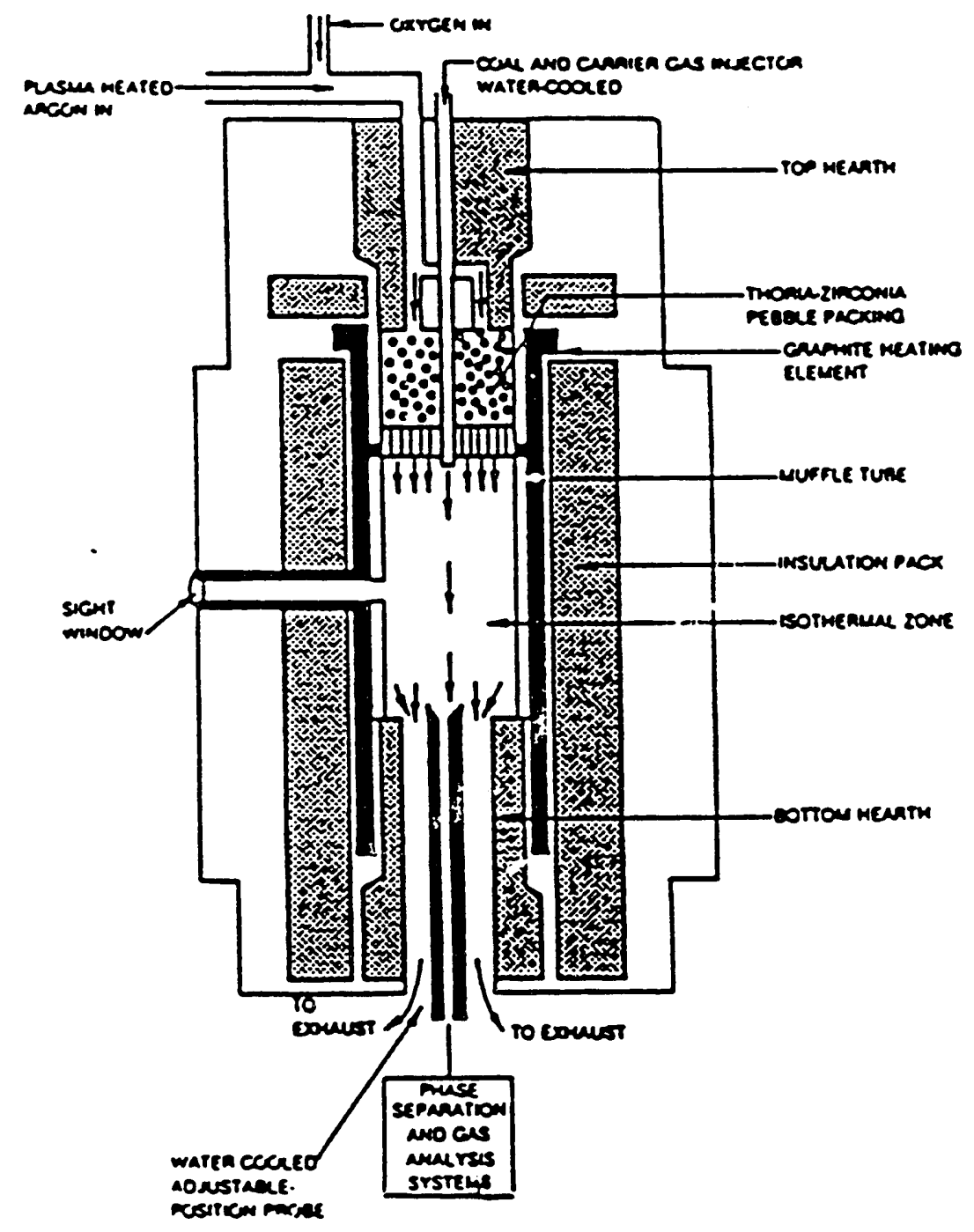




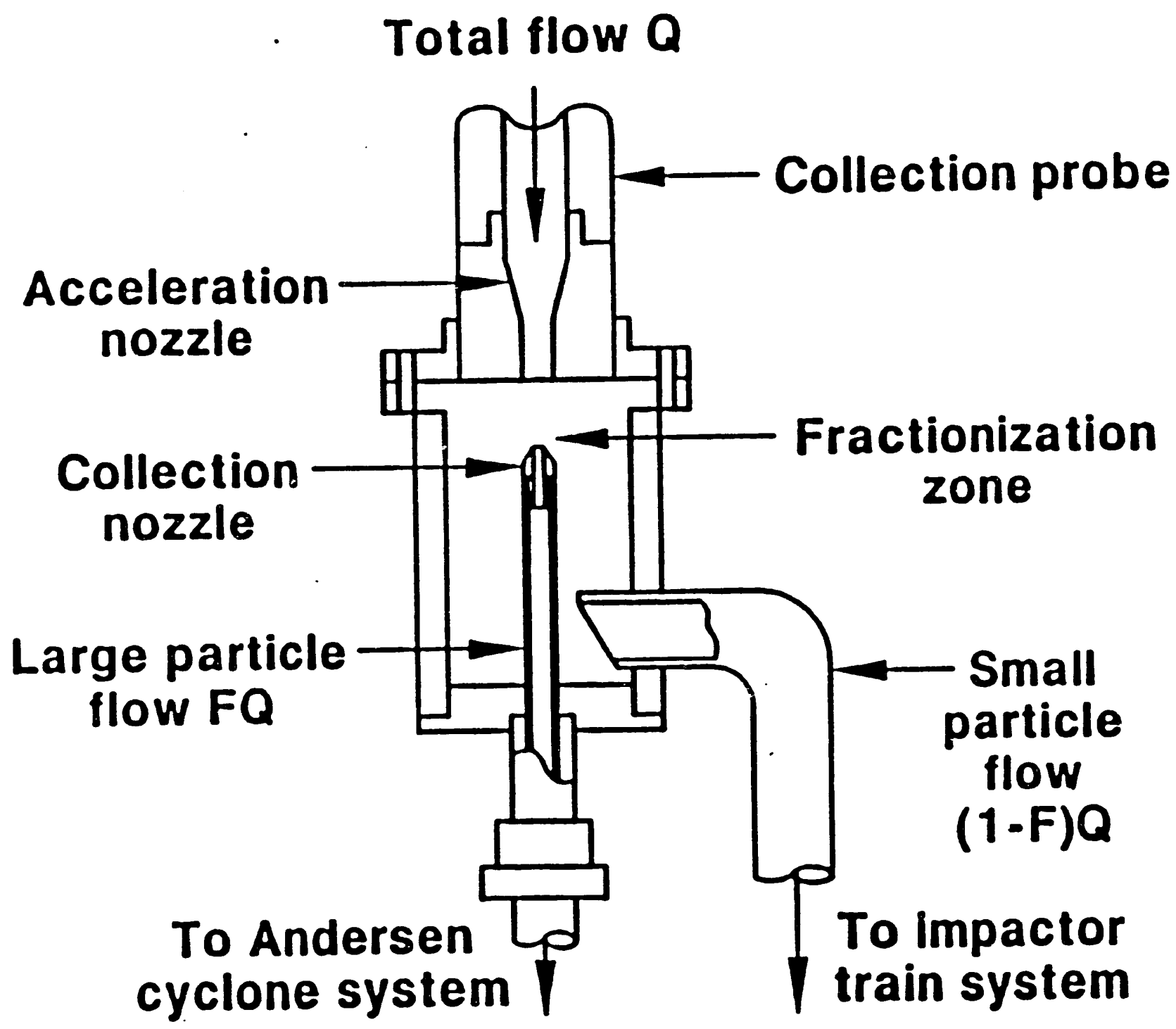


FIGURE 3

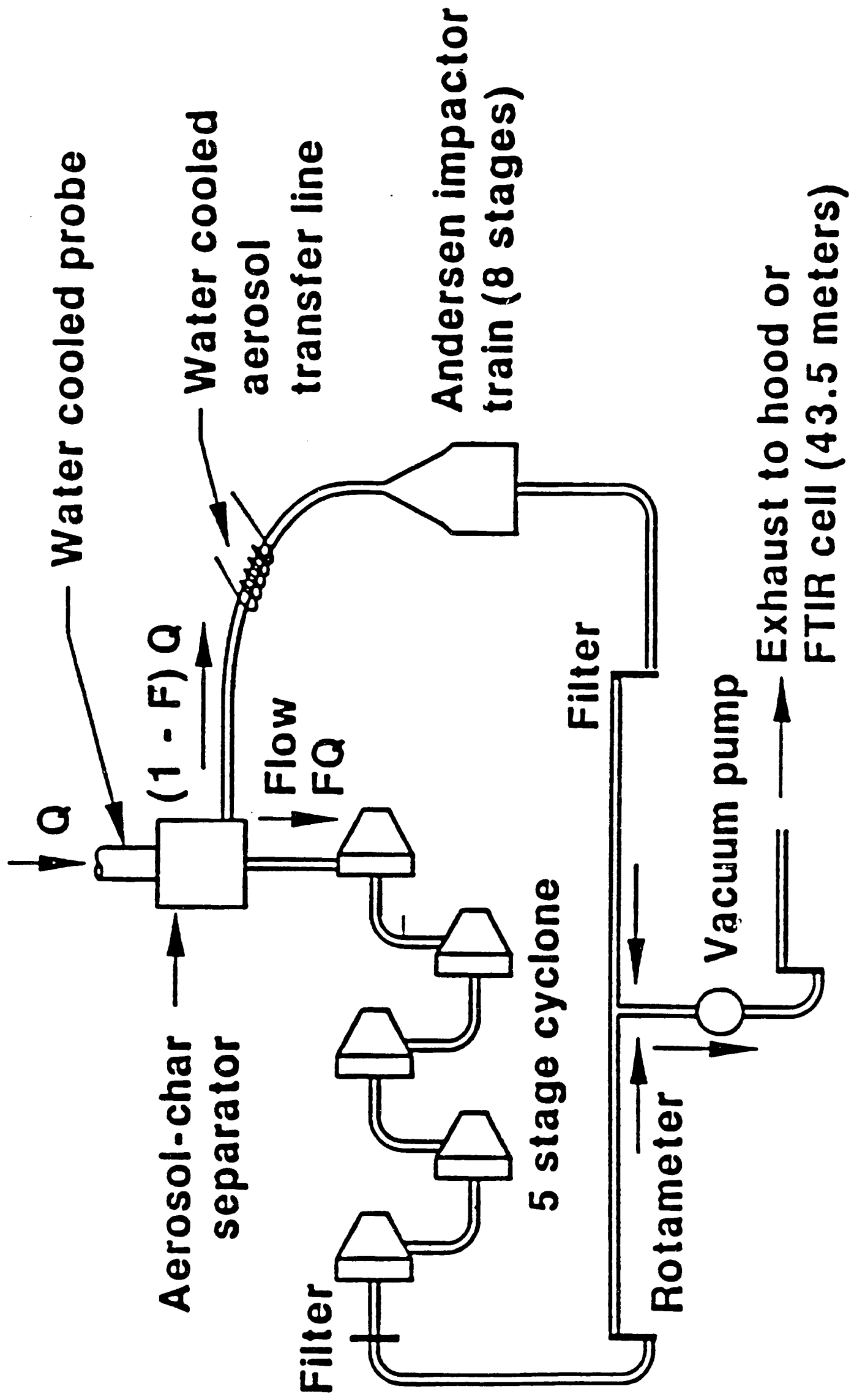




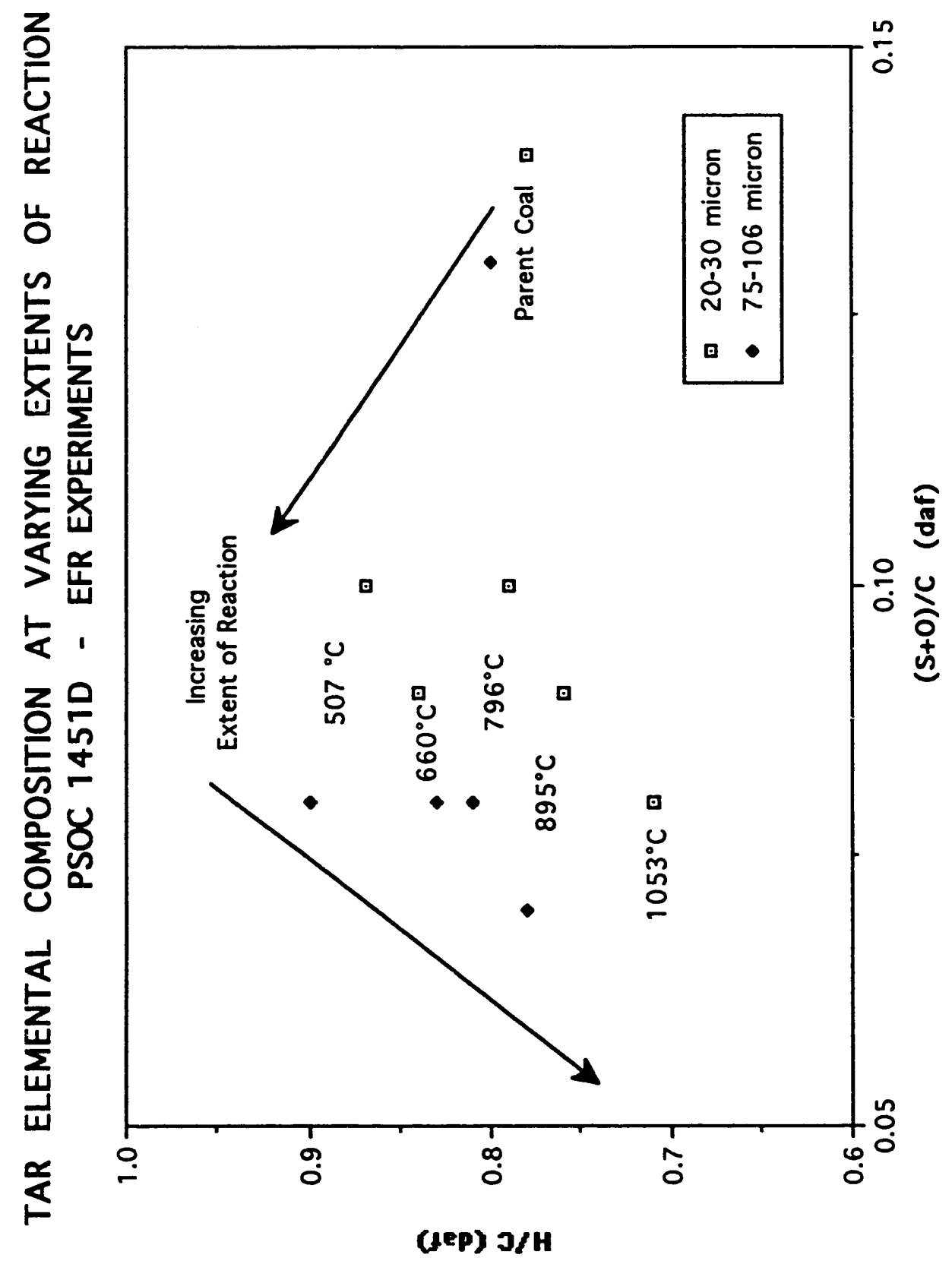


FIGURE 5

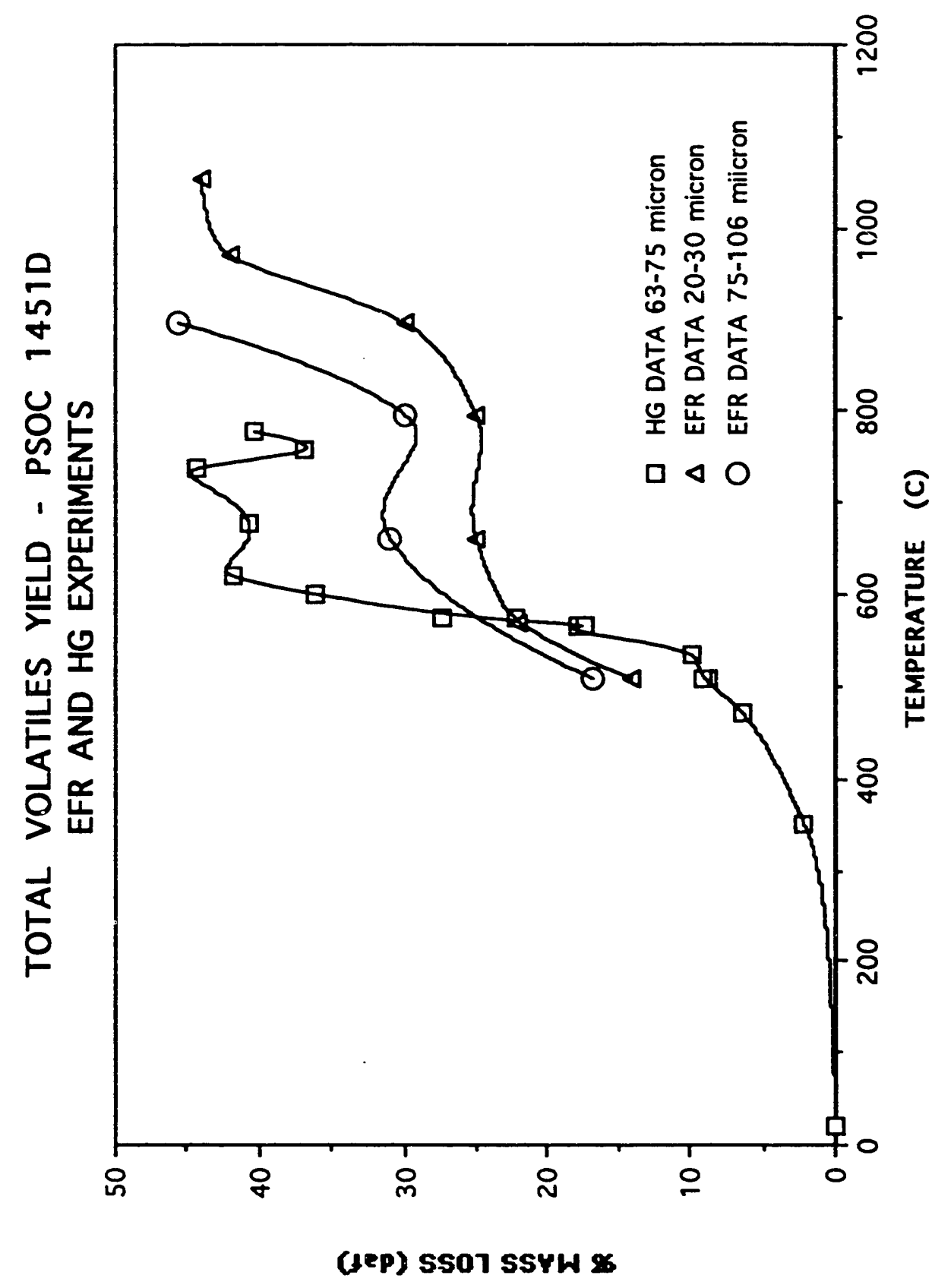


FIGURE 6

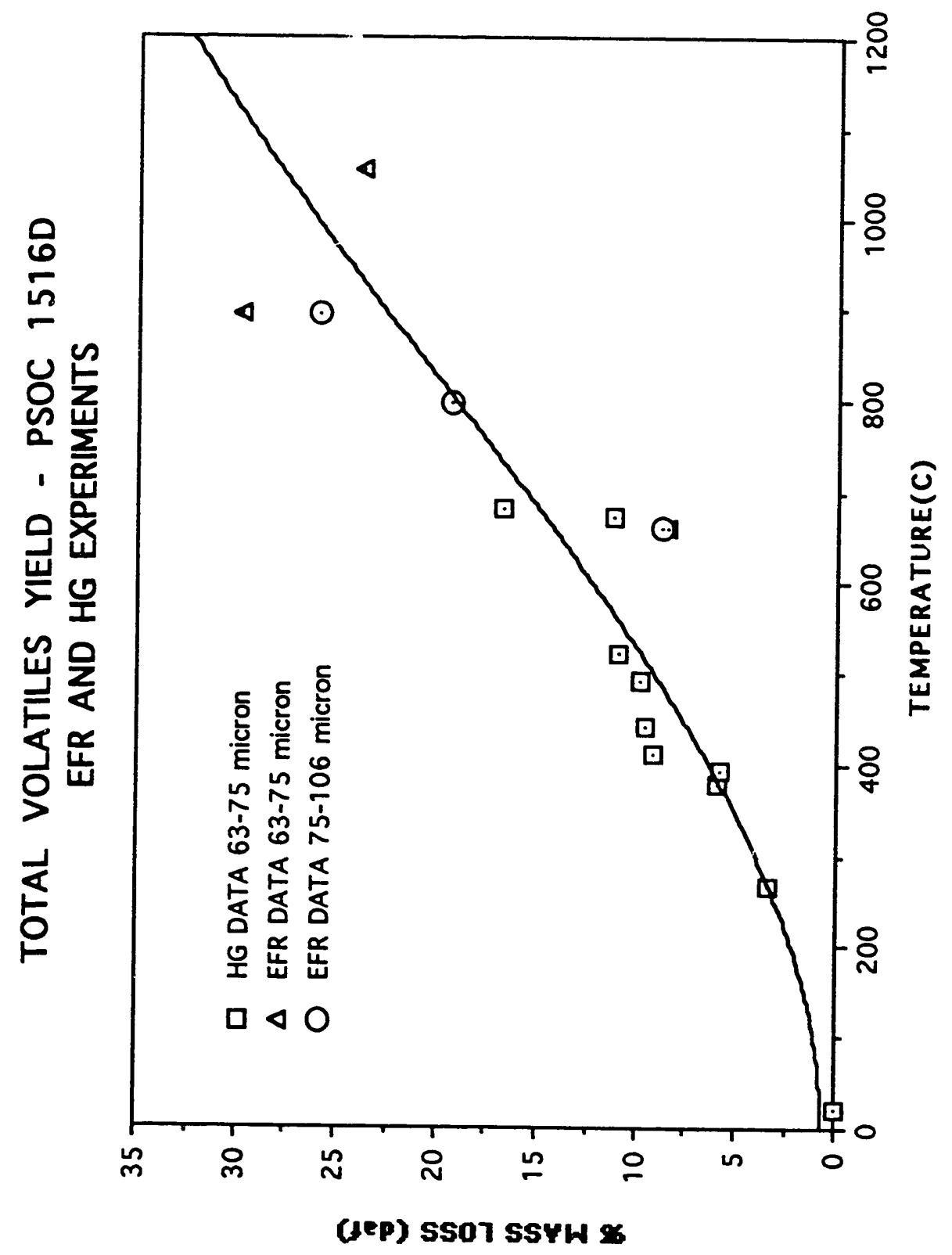




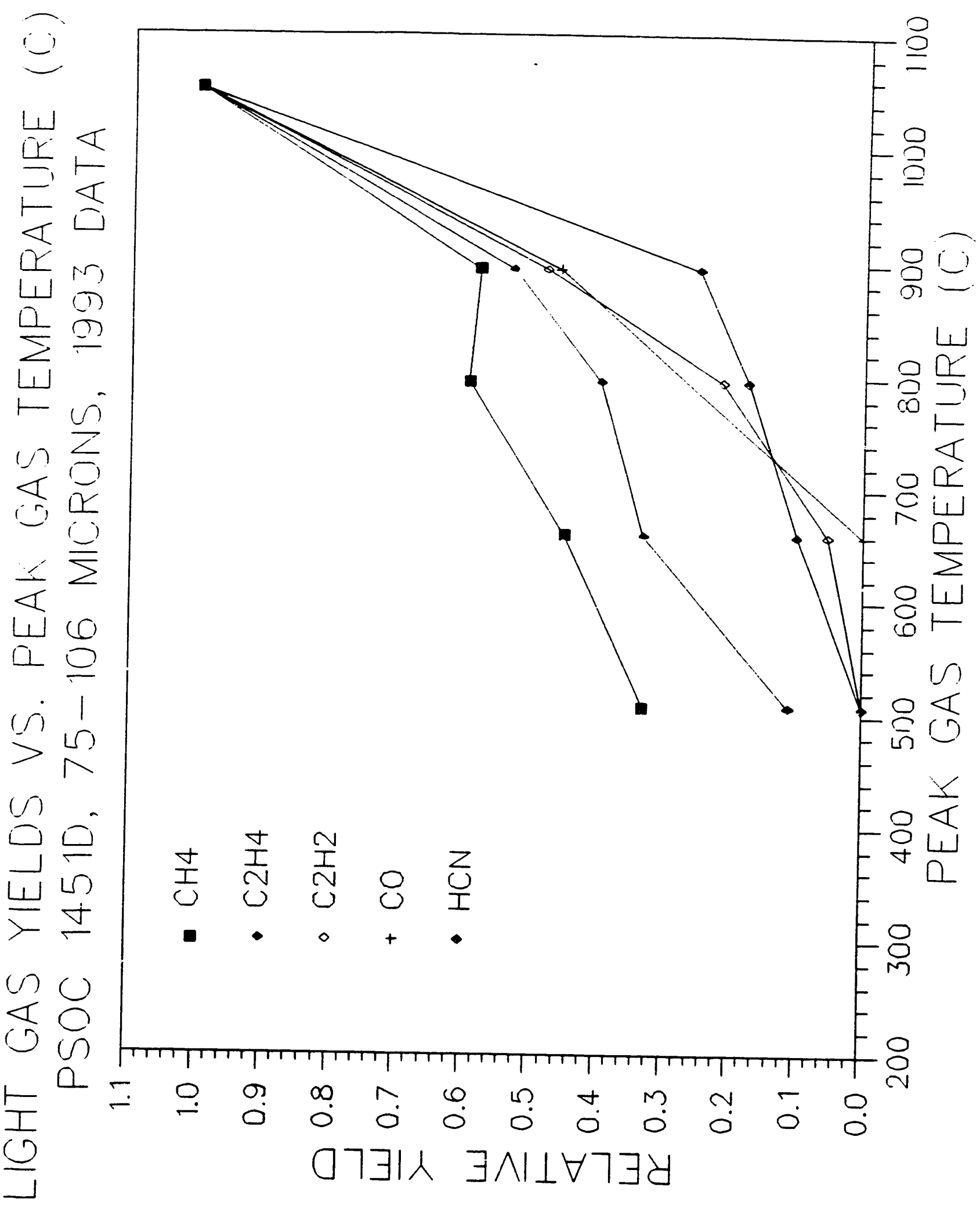




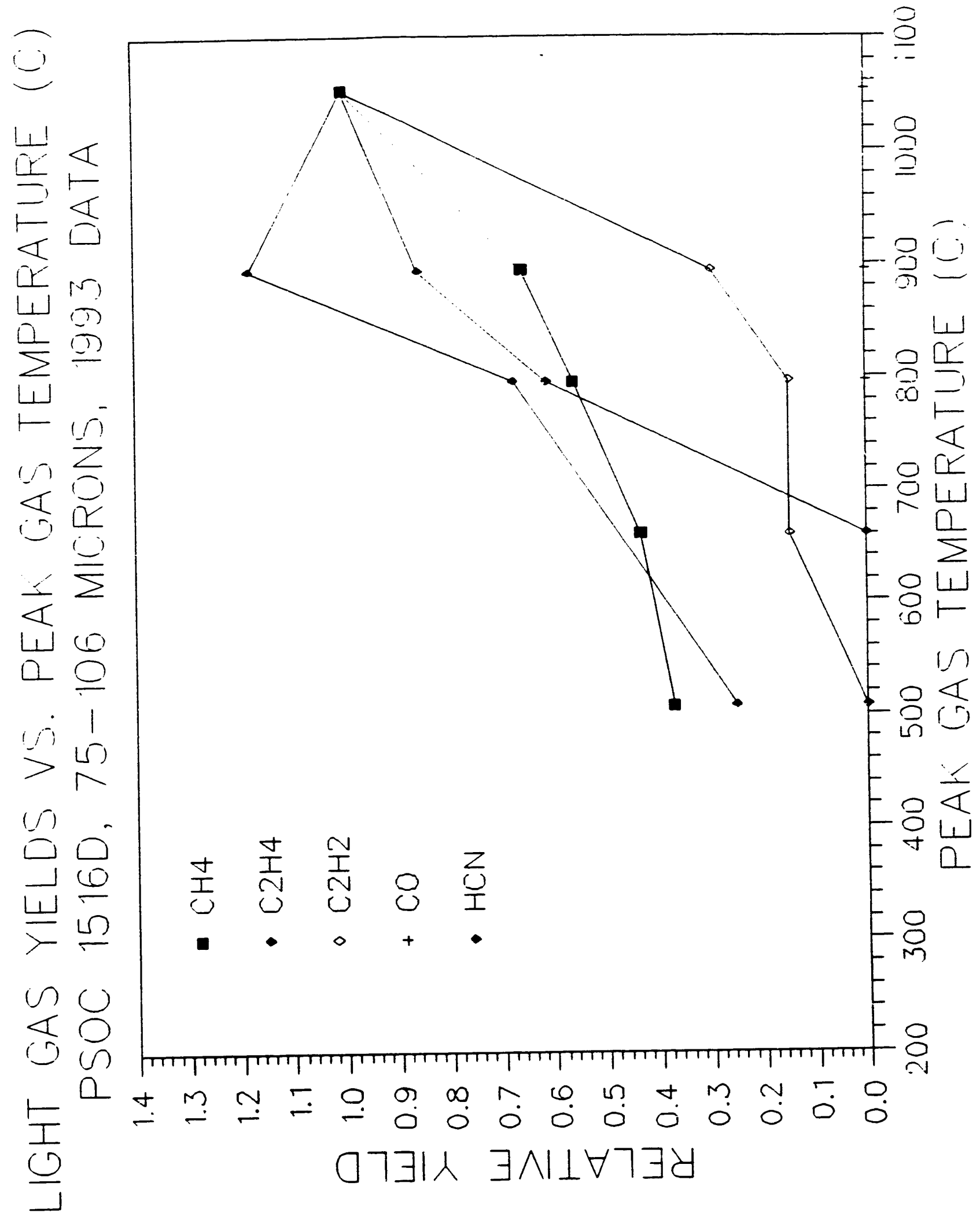




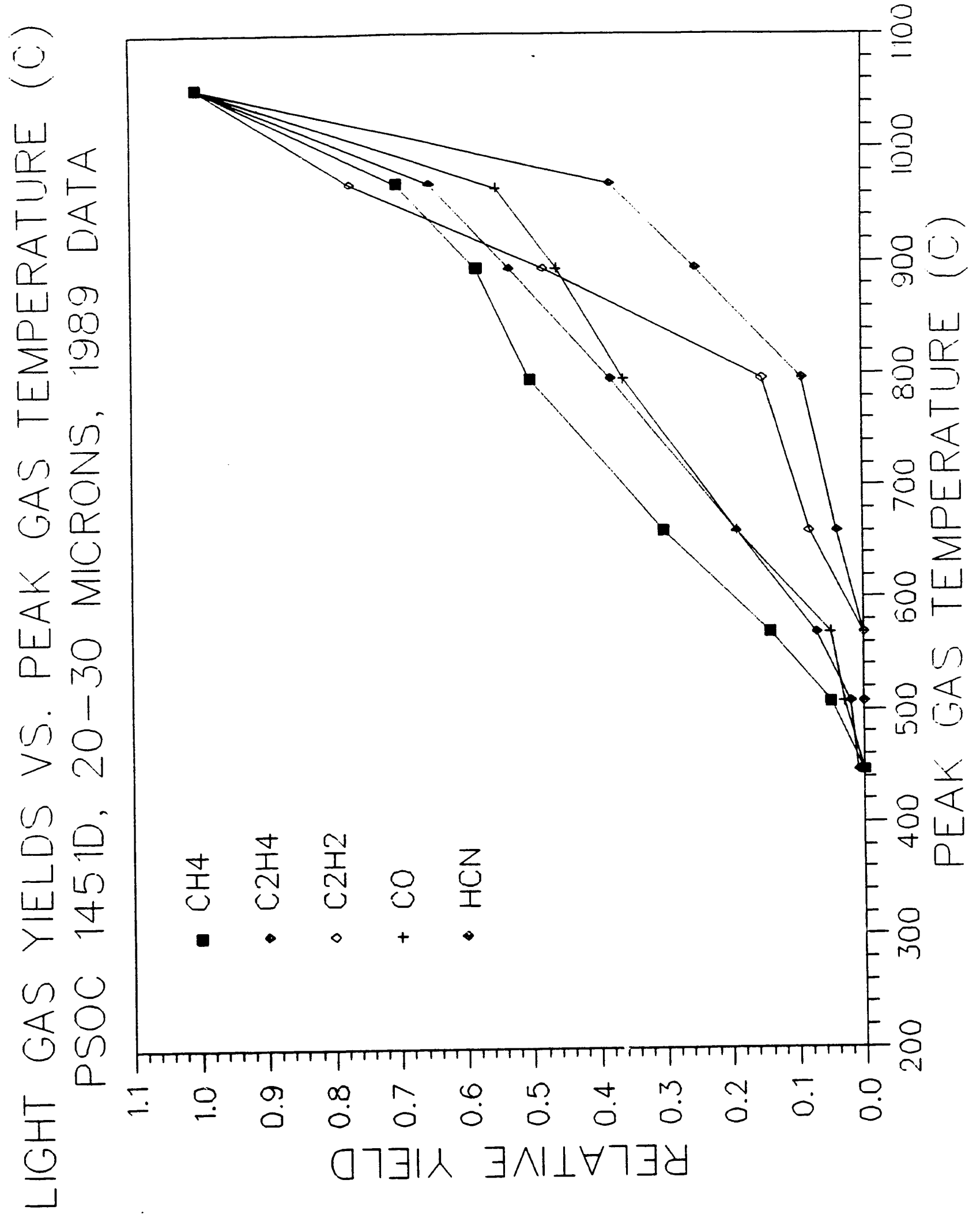




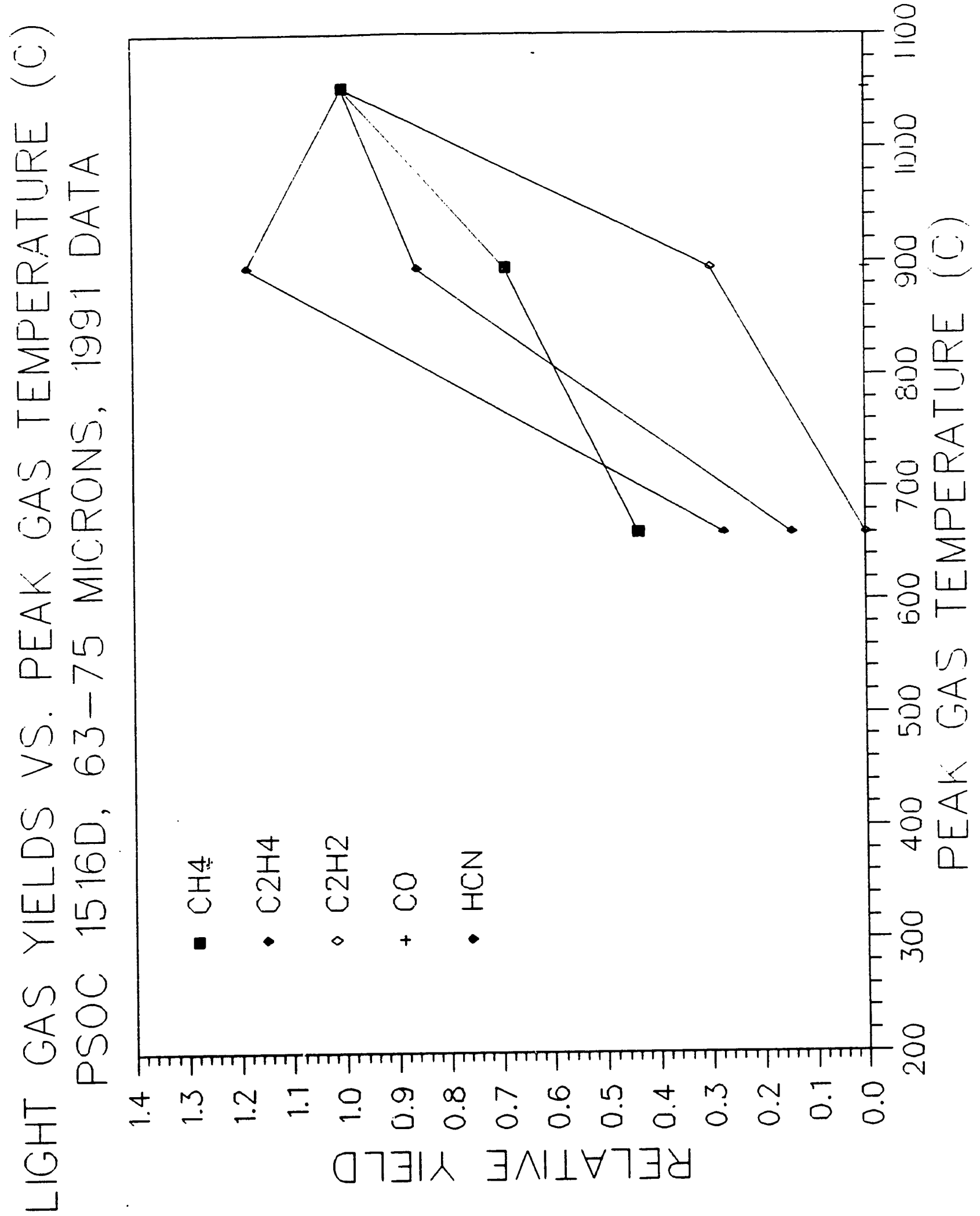


Log-probablity distribution for coal PSOC 1451d

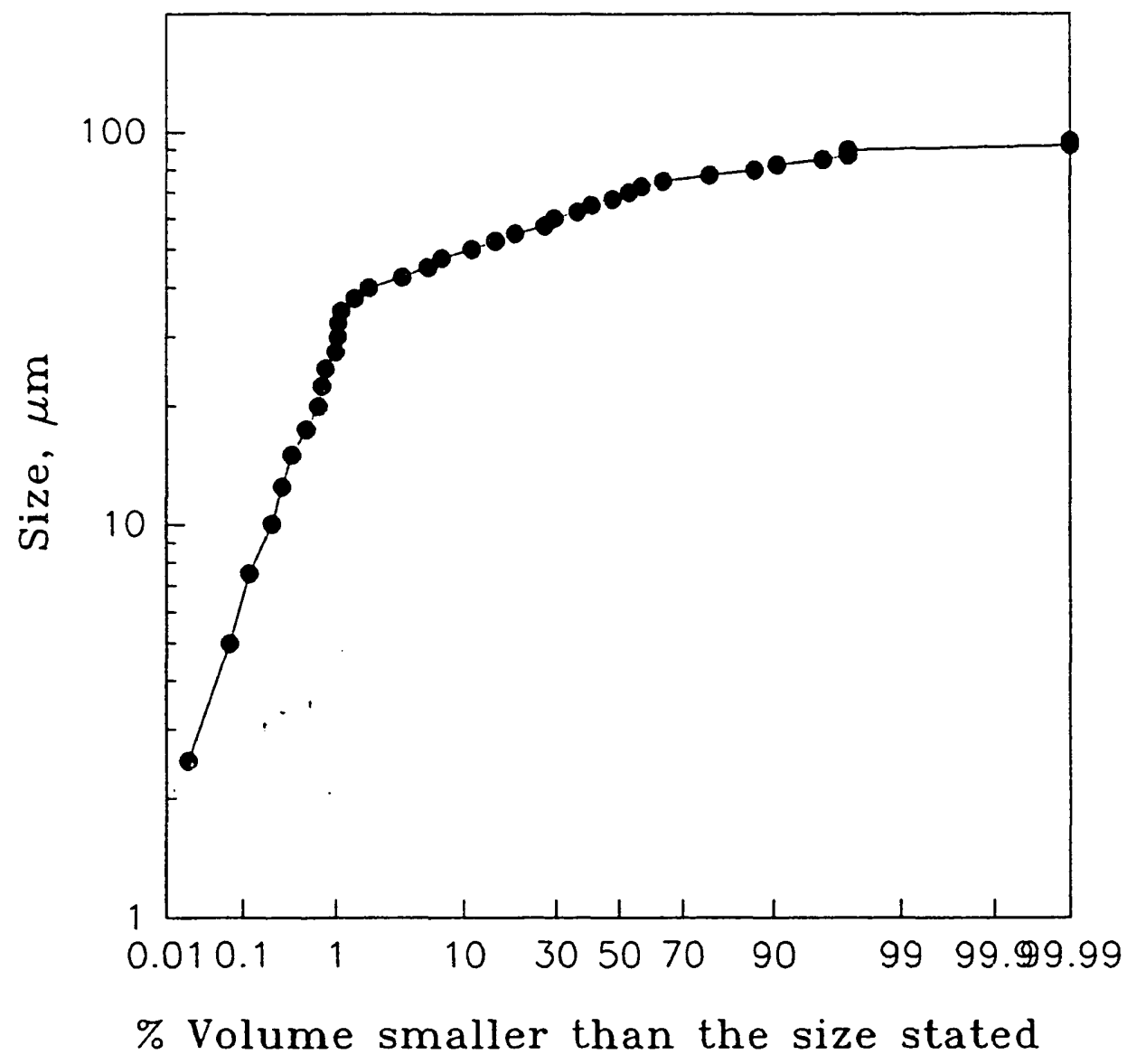


Log-probablity distribution for coal PSOC 1516d

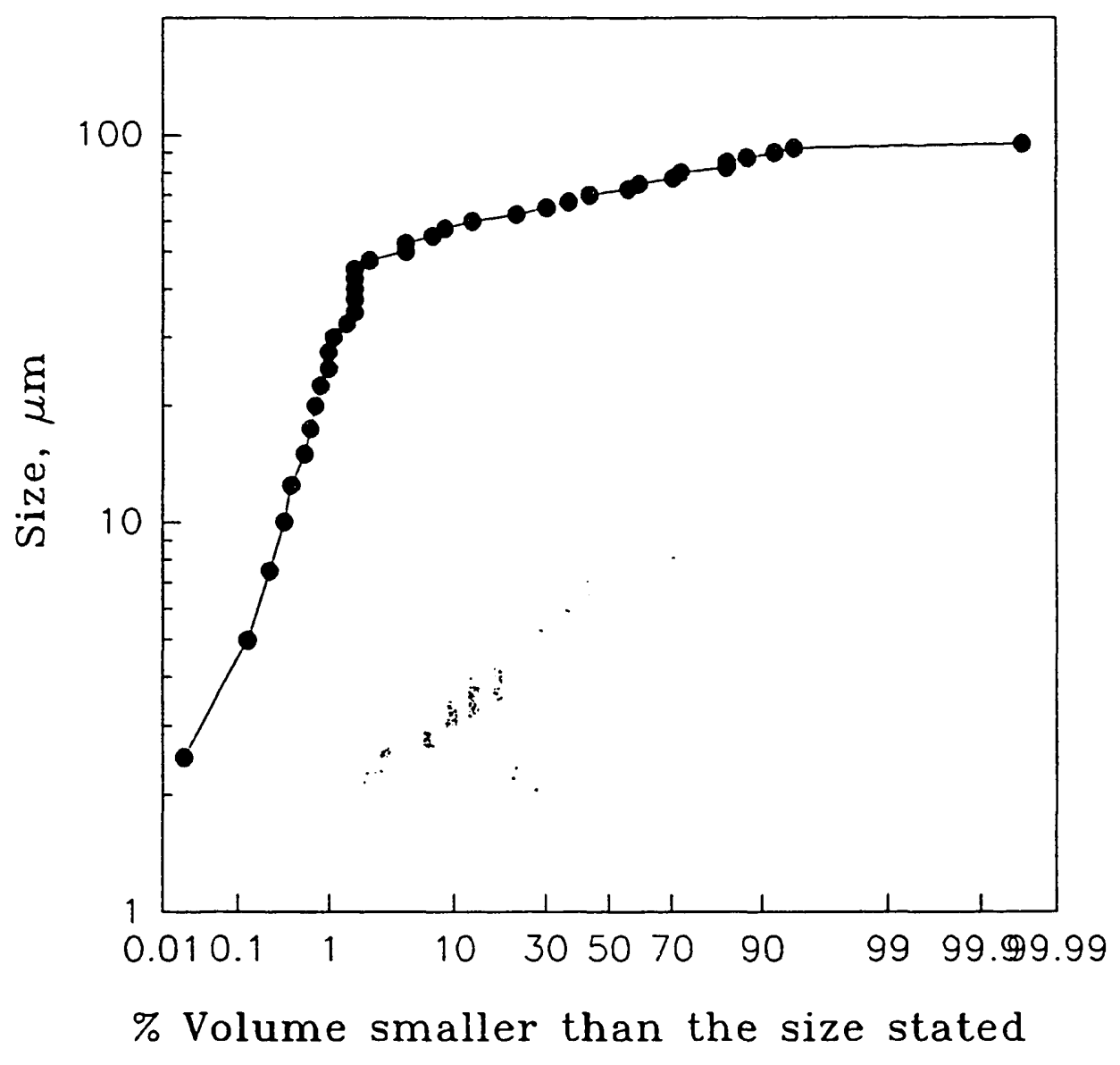


Differential size distribution for coal PSOC 1451d

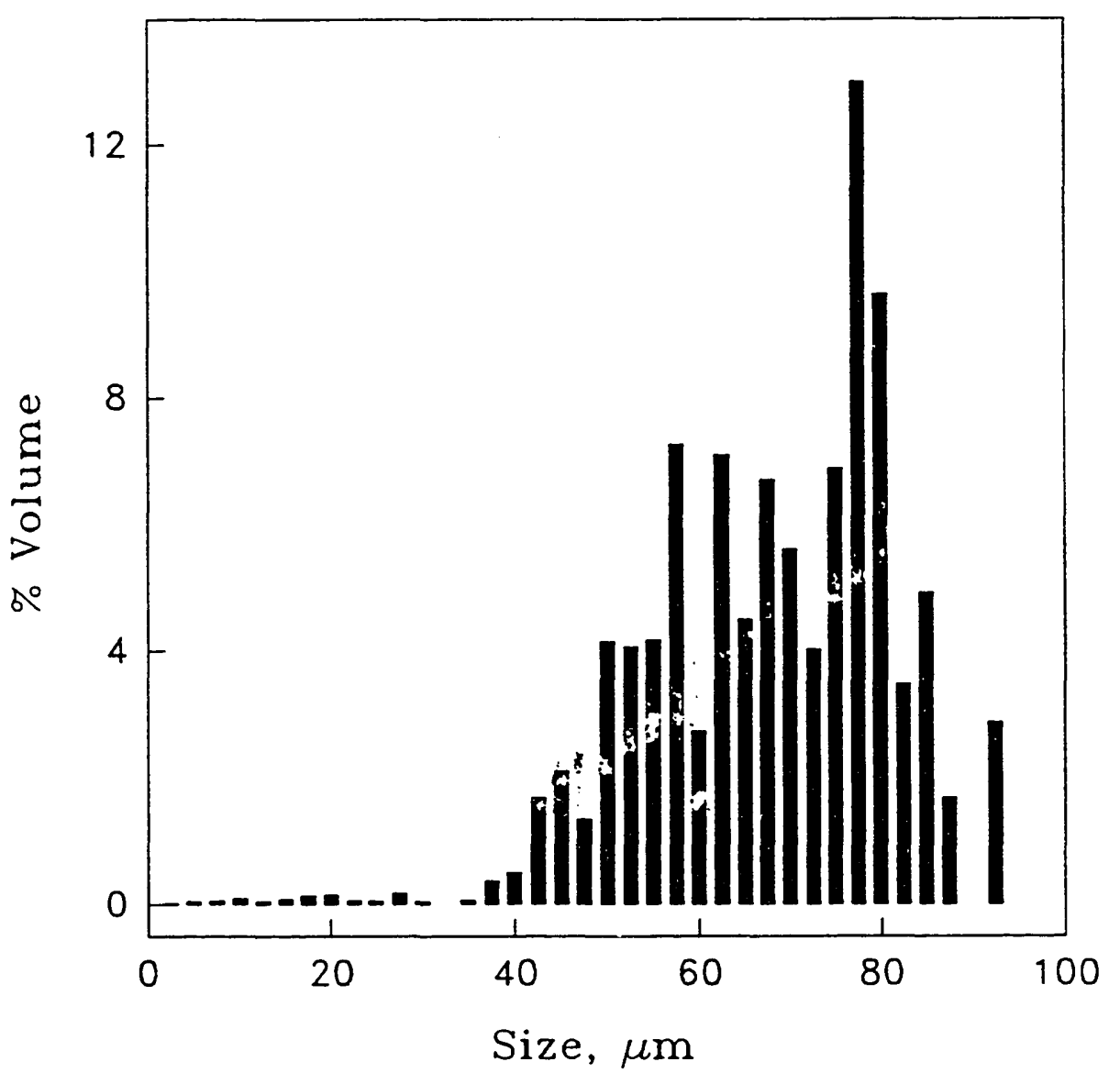


Differential size distribution for coal PSOC 1516d

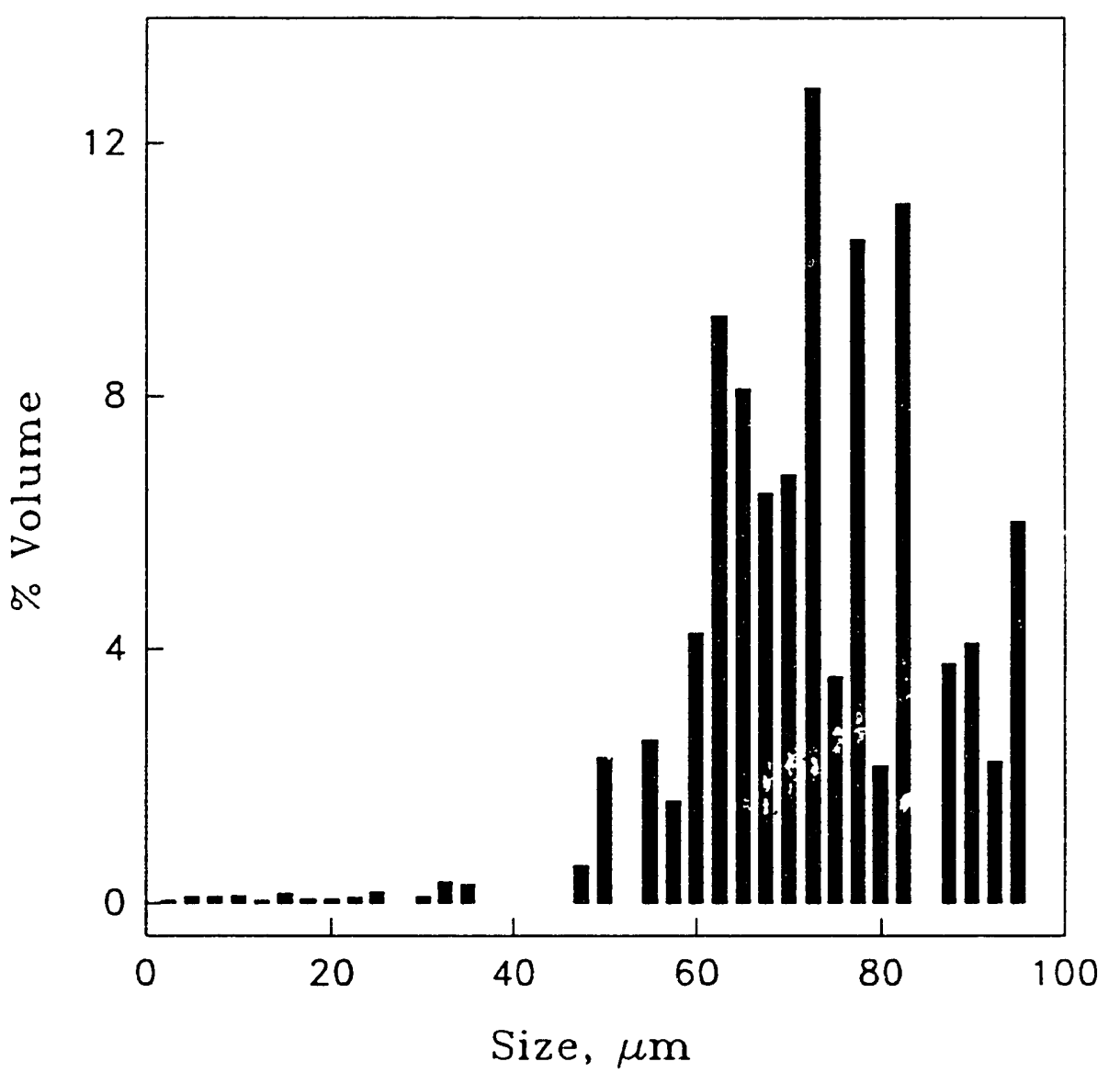



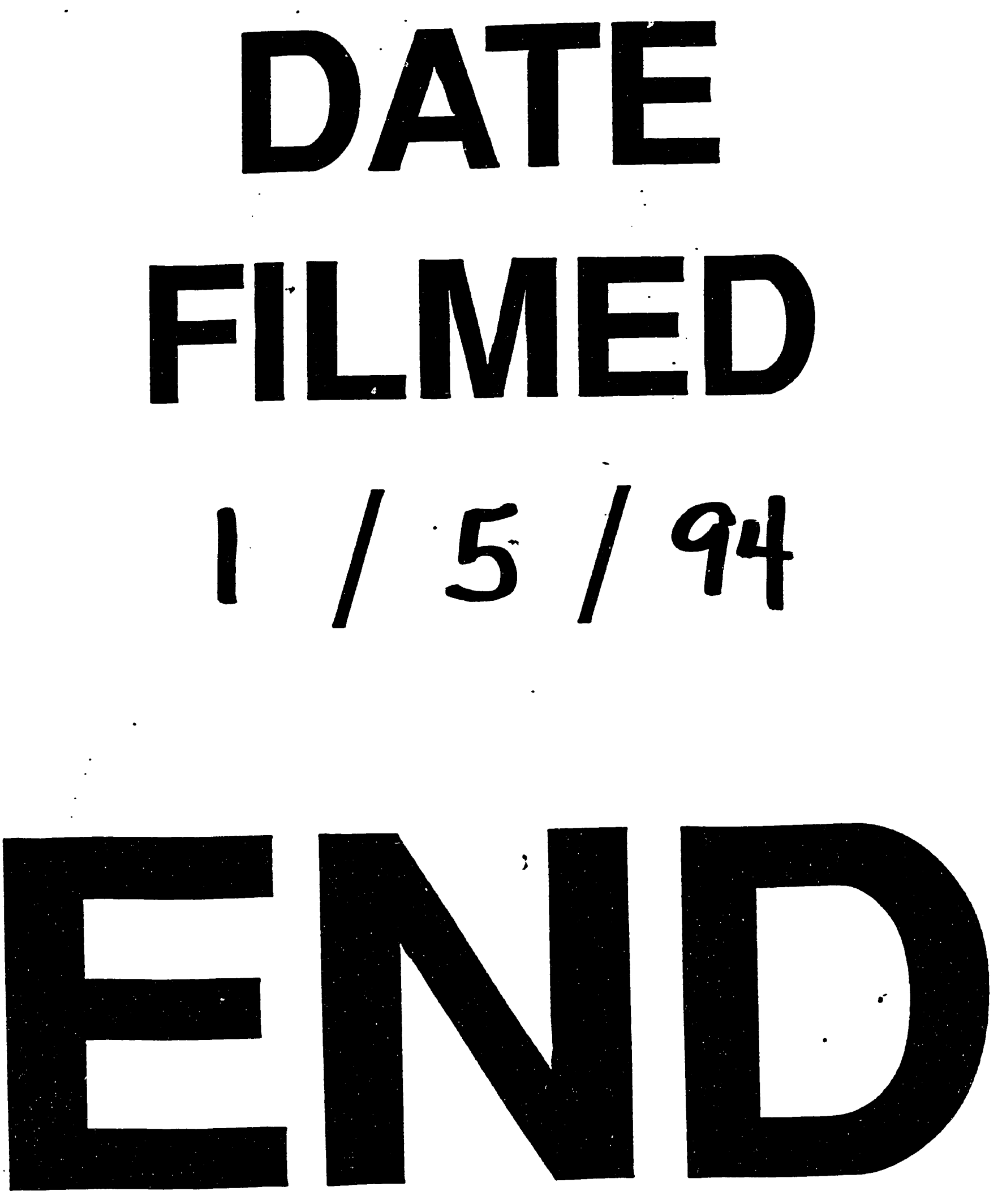